Pragnadyuti Mandal, MD

Medical College

Kolkata, India

Souvik Ghosh, MD

Midnapore Medical College

India

Shirsendu Mondal, MD

Medical College

Kolkata, India

Debasis Sanyal, MD

KPC Medical College

Kolkata, India

Sagar Basu, DM

Calcutta National Medical College

Kolkata, India

Swapan Jana, MBBS

Calcutta National Medical College

Kolkata, India

Address for Correspondence:

Pragnadyuti Mandal, MD

Calcutta National Medical College

Kolkata, India

Email: pdmandaldr@gmail.com

Received, 27 March, 2015

Accepted, 9 April, 2015

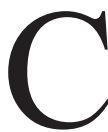

lobazam is an effective and safe broad spectrum antiepileptic drug and is used mainly as add-on drug in intractable epilepsies. Tolerance may develop on long term use but benefit figure may reach up to $28 \%{ }^{3,8,12}$

\section{Effectiveness of Clobazam as Add-on Drug in Intractable Epilepsies}

Twenty to forty percent of patients remain intractable to first line antiepileptic medicines. Clobazam is used as an add-on medicine in treatment of intractable epilepsies.

This study evaluated the effectiveness of clobazam as add-on drug in intractable epilepsy patients receiving either valproic acid or carbamazepine.

This study is an open label, data based clinical study which was undertaken in a neurology outpatient department of a tertiary care centre.

In this study, clobazam was added to epileptic patients who were receiving either valproic acid (VPA) or carbamazepine (CBZ) at maximum clinically tolerated dose. The effectiveness of clobazam was measured by percentages of reduction of seizure frequency from base line $(0 \%, 0-49.9 \%, 50-99.9 \%, 100 \%)$ and the responder rate $(50 \%$ or greater reduction of seizure frequency from base line).

Fisher's test and Chi-square test were used for data analysis.

Out of total 83 patients (62 male, 21 female, age range 14-60 years, mean age 24.5), 50 and 33 were receiving carbamazepine and sodium valproate respectively. All complex partial seizure (CPS) and $42.3 \%$ of generalized tonic clonic seizure(GTCS) patients became seizure free. The responder rate for GTCS cases were $67.3 \%$. The percentages of seizure free patients in VPA and CBZ group were $39.4 \%$ and $38 \%$ respectively. Seizure frequency reduction and responder rate were found to be significant $(\mathrm{p}<$ $0.05)$ between group.

Key Words: refractory epilepsy, clobazam, add-on treatment

Twenty to $40 \%$ of epilepsy patients remain intractable to monotherapy. Diagnostic criteria for defining intractable epilepsy vary considerably. ${ }^{1,4,6,11}$ The epilepsy patients who become resistant to treatment with one or more primary drugs at maximum clinically tolerated dose are included 
in the true intractable category. ${ }^{14}$

The objective was to assess clinically, the effectiveness of clobazam as add-on drug in intractable epilepsy.

\section{Materials and Methods}

The study was an open-label, data based, clinical study that was initiated after obtaining Institutional Ethics Committee approval. Study duration was one and half year. Informed consent from each patient was obtained in vernacular. Epileptic patients were classified and categorized as per International league against Epilepsy classification. For the study, patients with age of 14 years and above of either sex were enrolled in the Neuromedicine outpatient Department of a tertiary care centre. Epileptic patients with seizure types of generalized tonic clonic seizure (GTCS), complex partial seizure (CPS), simple partial seizure (SPS), SPS with secondary generalization and absence seizure were included for the study. The patients who were excluded from the study were patients with age less than 14 years, liver \& kidney disease patients, severe mental retardation, progressive neurological disease patients, alcohol and drug addicts and females with pregnancy . Also patients with seizures due to structural CNS lesion, drug and acute medical illness and seizure syndrome were excluded from the study.

The epileptic patients were receiving either valproic acid (VPA) or carbamazepine (CBZ) at maximum tolerated dose still was having one or more seizure per month. Baseline seizure frequency per month was calculated from the last 3 months average seizure frequency. Each patient was evaluated by detail history, physical examination and neurological examination. Necessary investigations were done. Patients were asked to keep a seizure diary. Clobazam was used in a dose of 5-20mg/day. Patients were asked to come for follow up once in every 2 weeks (next week if defaulted). Patients were assessed clinically during follow up and seizure diary was checked in each visit. Detail history about drug compliance, adverse effects and seizures were taken in follow up visits.

Efficacy of Clobazam as add-on drug was assessed by the following parameters -

1. Percentage of seizure free patients- It means $100 \%$ reduction of seizure frequency from baseline seizure frequency.

2. Percentage reduction of seizure frequency from baseline frequency- it may be $0-49.9 \%, 50-99.9 \%$.

3. Responder rate- $50 \%$ or greater reduction of seizure frequency from baseline.

We carried out intention to treat analysis for seizure outcome. Fisher's test and Chi-square Test were used for data analysis.

\section{Results}

In this study, 83 intractable epilepsy cases of different ages ranging from 14 years to 60 years of both male (62 patients) and female (21 patients) were enrolled. Distribution of patients according to types of seizures was as follows: GTCS - 52, CPS-10, SPS-5, and SPS with secondary generalization -11 , Absence- 5.55 patients were receiving carbamazepine and 33 patients were receiving valproic acid (Table 1). In the total 18 months study period, 75 patients completed follow up for 6 months, 31 patients completed 18 months follow up, 5 patients dropped out after baseline assessment and 3 patients dropped out after assessment at $2^{\text {nd }}$ week. We followed the intention to treat analysis for the drop out patients.

The effect of clobazam as add-on drug for specific types of seizure was analyzed. For generalized tonic clonic seizure patients $(n=52),>50 \%$ reduction in seizure frequency was observed in $25 \%$ of patients, $<50 \%$

\begin{tabular}{|c|c|c|c|c|c|c|c|c|}
\hline $\begin{array}{l}\text { Types of } \\
\text { seizure }\end{array}$ & Male & Female & Total & $\begin{array}{l}\text { Mean } \\
\text { Age }\end{array}$ & $\begin{array}{l}\text { Valproic } \\
\text { acid }\end{array}$ & $\begin{array}{l}\text { Carbam- } \\
\text { azepine }\end{array}$ & Total & $\begin{array}{l}\text { Median } \\
\text { seizure } \\
\text { frequency }\end{array}$ \\
\hline GTCS & $\begin{array}{l}34 \\
(54.8 \%) \\
\end{array}$ & $\begin{array}{l}18 \\
(85.7 \%) \\
\end{array}$ & $\begin{array}{l}52 \\
(62.7 \%) \\
\end{array}$ & 26.19 & $18(54.5 \%)$ & $34(68 \%)$ & $52(62.7 \%)$ & 2.00 \\
\hline CPS & $\begin{array}{l}09 \\
(14.5 \%)\end{array}$ & $01(4.8 \%)$ & $10(12 \%)$ & 21.10 & $05(15.2 \%)$ & $05(10 \%)$ & $10(12 \%)$ & 1.50 \\
\hline SPS & $03(4.8 \%)$ & $02(9.5 \%)$ & $05(6 \%)$ & 28.00 & 0 & $05(10 \%)$ & $05(6 \%)$ & 5.00 \\
\hline $\begin{array}{l}\text { SPS with } \\
\text { general- } \\
\text { ization }\end{array}$ & $\begin{array}{l}11 \\
(17.7 \%)\end{array}$ & 0 & $\begin{array}{l}11 \\
(13.3 \%)\end{array}$ & 26.00 & $05(15.2 \%)$ & $06(12 \%)$ & $11(13.3 \%)$ & 4.00 \\
\hline Absence & $05(8.1)$ & 0 & $05(6 \%)$ & 15.00 & $05(15.2 \%)$ & 0 & $05(6 \%)$ & 2.00 \\
\hline Total & 62 & 21 & 83 & 24.54 & 33 & 50 & 83 & 3.00 \\
\hline
\end{tabular}

Table 1: Distribution of seizure type according to sex, mean age, primary drug use and median seizure frequency 


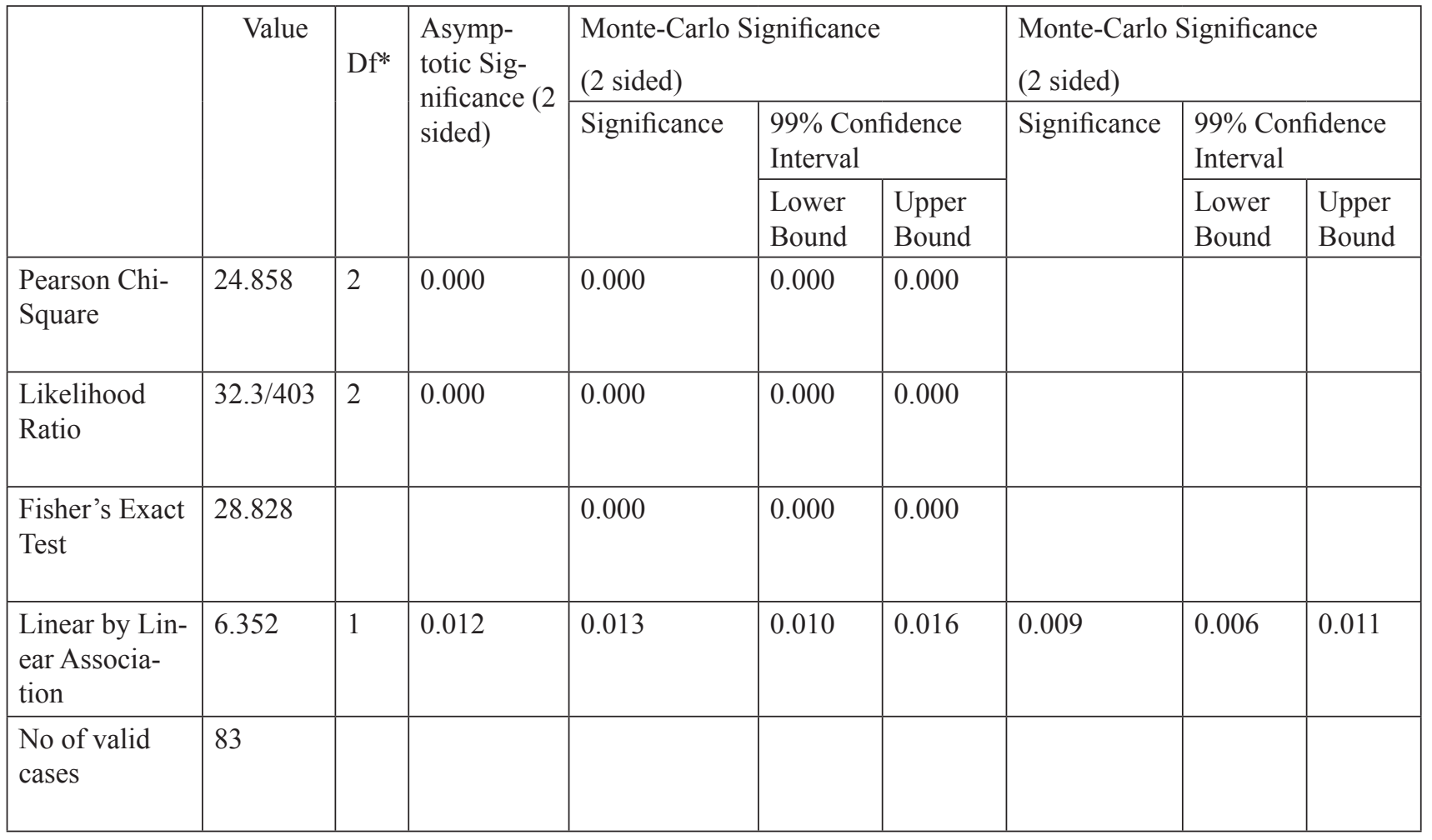

\#Chi-square test was applied on results which were expressed in percentages, $\mathrm{p}<0.05$

*Df- degrees of freedom

Table 2: Chi-Square Test result: Reduction of seizure frequency according to seizure type\#

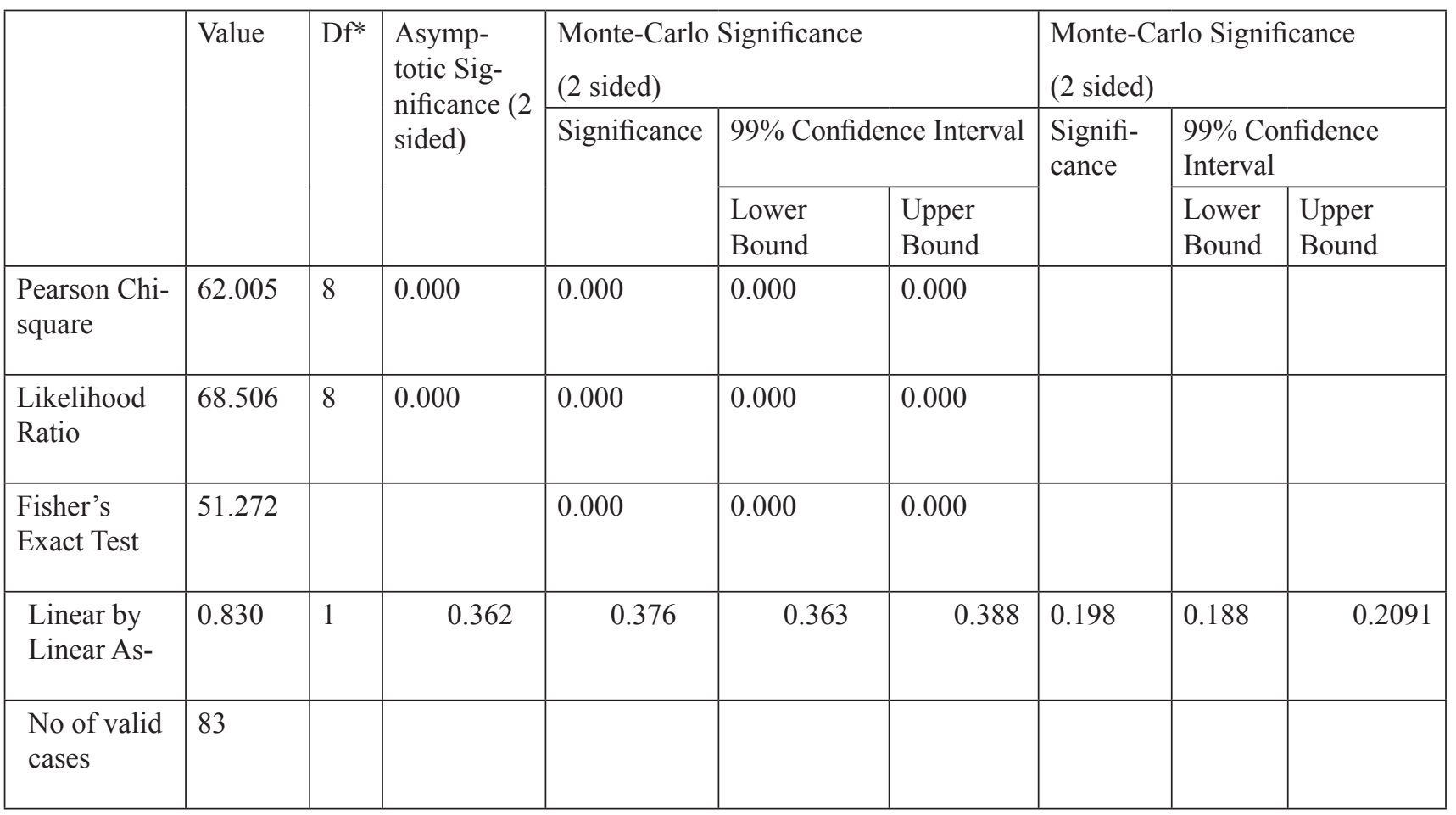

\#Chi- square test was applied on results which were expressed in percentages, $p<0.05$

Df- degrees of freedom

Table 3: Chi-square Test result: Reduction of seizure frequency according to first line drug used\# 
reduction in seizure frequency was observed in $32.7 \%$ of patients. The percentages of seizure free GTCS patients were $42.3 \%$ and responder rate was $67.3 \%$. All patients of SPS $(n=5)$, SPS with secondary generalized seizure $(\mathrm{n}=$ $11)$, absence seizure $(n=5)$ were in the $>50 \%$ reduction seizure frequency category. All $(\mathrm{n}=10)$ CPS patients became seizure free. The percentages of seizure free patients in both valproic acid $(\mathrm{n}=33)$ and carbamazepine $(n=50)$ groups were $39.4 \%$ and $38 \%$ respectively. $60.6 \%$ of VPA and $18 \%$ of CBZ group of patients were in the $>50 \%$ reduction in seizure frequency category, whereas $44 \%$ of CBZ and none in the VPA group of patients were in the $<50 \%$ reduction in seizure frequency category.

The statistical significance of reduction of seizure frequency in percentages according to seizure type (Table 2) and drug use (Table 3), when analyzed by applying Chisquare test and Fisher's test was found to be significant $(\mathrm{p}<0.05)$.

\section{Discussions}

In this study, patients with generalized tonic clonic seizure, $>50 \%$ reduction in seizure frequency was observed in $25 \%$ cases, $<50 \%$ reduction in seizure frequency was observed in $32.7 \%$ cases. The percentages of seizure free GTCS patients were $42.3 \%$ and the $50 \%$ responder rate was $67.3 \%$. All simple partial seizure patients were in the $<50 \%$ reduction in seizure frequency category. $>50 \%$ reduction in seizure frequency was observed in all SPS with secondary generalized seizure and absence seizure. All complex partial seizure patients became seizure free. The responder rate in generalized tonic-clonic seizure in this study concord with previous studies. ${ }^{7,13,15}$

The percentages of seizure free patients vary in different studies. ${ }^{2,7,9,10}$ The observation in open studies showed that clobazam produced a overall reduction of seizure frequency of $65 \%,{ }^{9}>$ or $=50 \%$ reduction of seizure frequency in $71 \%$ of the short term ( 2 months) subjects and $81 \%$ of the long term ( 6 months) subjects were observed by Sugai K. ${ }^{15}$ In a study in Japan by Kinoshita M et al, seizure control was achieved in $26 \%$ of CPS, $64 \%$ of SPS and $86 \%$ of GTCS patients. ${ }^{7}$ The Canadian clobazam co-operative group reported $>50 \%$ reduction of seizure frequency in $40-50 \%$ of patients with different seizure types. Percentage of seizure free patients, in their study was $10-30 \% .^{2}$ Montenegro et al in their add-on trial with clobazam in intractable partial seizure patients reported $>$ $50 \%$ improvement of seizure control in $49.4 \%$ cases and $<50 \%$ improvement of seizure control in $40.2 \%$ cases. $^{9}$ Age range in their study was 15 to $70 \mathrm{yrs}$. In another study, Montenegro reported $11 \%$ of seizure free patients on add-on clobazam..$^{10}$ Jan MM et al, in a cohort study in Middle East, reported 35.5\% seizure free cases, $45 \%$ had $>50 \%$ reduction of seizure frequency. ${ }^{5}$

In the present study, the response of clobazam as addon drug was also analyzed according to first line drug use. The percentages of seizure free patients according to first line antiepileptic drug use was almost similar in valproic acid $(39.4 \%)$ and carbamazepine (38\%) group. $60.6 \%$ of valproate treated and $18 \%$ of carbamazepine treated patients showed more than $50 \%$ reduction in seizure frequency. $44 \%$ of patients of carbamazepine group and none in the valproate group showed $<50 \%$ reduction of seizure frequency. The statistical significance of percentages of seizure reduction according to seizure type and drug use was assessed by Chi- square test and Fisher's exact test respectively. The test result was significant $(\mathrm{p}<0.05)$.

The most common side effect which was observed in this study was sedation. $21.6 \%$ (18 patients) of the study patients reported sedation. However no patient discontinued medicine or was withdrawn due to sedation. The percentages of sedation differ in studies like $38 \%$ by Robertson M, 32\% by Canadian clobazam co-operative group. ${ }^{2,13}$

Conclusion: It may be concluded that clobazam is an effective add-on drug for treatment of intractable epilepsies but response varies according to type of seizure and primary drug used.

Financial Disclosure: No financial support was received from any source

Acknowledgements: We gratefully acknowledge the Principal, Calcutta National Medical College, Kolkata, India for giving permission for conducting the study .

\section{References}

1. Aicardi J, Shorvon SD. Intractable epilepsy. In: Engel J (Jr), Pedley TA, editors. Epilepsy: a comprehensive textbook, vol-2. Philadelphia. Lippincott Raven Publishers 1998: p1325-1330

2. Canadian Clobazam Co-operative group. Clobazam in treatment of refractory epilepsy: the Canadian experience. A retrospective study. Epilepsia 32: 407-416, 1991

3. Gastaut H, Low MD. Antiepileptic properties of clobazam, a 1,5 - benzodiazepine in man. Epilepsia 20: $437-446,1979$

4. Gilman JT, Duchowny M, Jayakar P, Resnick TH. Medical Intractability in children evaluated for surgery. Neurology 44: 1341-1343, 1994

5. Jan MM et al. Clobazam for the treatment of intractable childhood epilepsy. Neurosciences 


\section{Mandal et al}

(Riadh) 5: 159-161, 2000

5. Juul Jensen P. Epidemiology of intractable epilepsy. In: Schmidt D, Morsellie P, editors. Intractable epilepsy. New York. Raven Press 1986: p5-11

6. Kinoshita $\mathrm{M}$ et al. Efficacy of low dose, addon therapy of clobazam is produced by its major metabolite, N-desmethyl-CLB. J Neurol Sci 263: 44-48, 2007

7. Montenegro MA, Arif H, Nahm EA, Resor SR Jr, Hirsh LJ. Efficacy of Clobazam as add-on therapy for refractory epilepsy: Experience at a US Epilepsy Centre. Clinical Neuropharmacology 31: 333-338, 2008

8. Montenegro MA, Candas F, Noronha AL. Mory SB, Curvalho MI, Marques LH, Guerreiro CA. Efficacy of Clobazam as add-on therapy in patients with refractory partial epilepsy. Epilepsia 42: 539-542, 2001

9. Montenegro MA. Efficacy of clobazam as add-on therapy for refractory epilepsy: experience at a US epilepsy centre. Clin Neuropharmacol 31: 333-338, 2008

10. Ohtsuka Y, Ogino T, Amano R, Yamatogi Y, Oka E, Ohtahara S. Rational treatment of refractory epilepsy in childhood. Jpn J Psychiatry Neurology 42:443447, 1988

11. Remy C, Clobazam in the treatment of epilepsy: a review of the literature. Epilepsia 35: S88-91, 1994

12. Robertson MM. Current status of the 1, 4 and 1,5 benzodiazepines in treatment of epilepsy: the place of clobazam. Epilepsia 27: S7-41, 1986

13. Schmidt D. Medical intractability in partial epilepsies. In: Luders H, editors. Epilepsy Surgery. New York. Raven Press 1991: p 83-90.

14. Sugai K. Clobazam as a new antiepileptic drug and clorazepate dipotassium as an alternative antiepileptic drug in Japan. Epilepsia 45: S20-2, 2004 